\title{
Improving Resilience and Combating Burnout in US Army Health Care Teams
}

\author{
Alyssa M. Coleman, MPH, CPH, Meredith M. Hartzell, PhD, \\ Robert C. Oh, MD, MPH, CASQM, Tamara S. Funari, RN, MSN, MMAS, ACNS-BC, \\ L. Omar Rivera, PhD, and Jill A. Brown, PhD
}

Introduction: In 2015, the Army Office of the Surgeon General adapted a Veterans Health Administration course for health care teams to implement holistic health practices to improve the resiliency of health care teams and patient care. The Army course Move to Health was piloted in health care teams at 8 military clinics. During the 20-hour course, health care teams learned techniques to improve their resiliency and created action plans to incorporate holistic health into the workplace, a known factor in decreasing burnout.

Methods: A process and outcome evaluation of this course was conducted using a within-group design. Surveys were administered to health care teams at precourse and 2-month follow-up, and 186 participants completed both surveys.

Results: Burnout among team members did not significantly change from precourse $(52 \%, \mathrm{n}=96)$ to follow-up $(48 \%, n=90)$. At follow-up, team members described using resiliency building strategies for self-care, significantly improved their self-efficacy to treat patients holistically in the patient-centered care home model, and reported increased satisfaction with patient centered care home (all are $p<0.01)$. However, $70 \%(n=131)$ of team members reported that they had not completed action plan implementation and did not report improved job satisfaction.

Discussion: Informed by the literature, Move to Health combines an individual resiliency intervention with organizational change, facilitating action plans to mitigate burnout. This manuscript explores potential reasons for why burnout did not significantly change within the 2 -month period following the intervention. Reducing burnout among health care teams is vital to ensure that optimal health care is provided to the military and its beneficiaries. (J Am Board Fam Med 2020;33:440-445.)

Keywords: Follow-Up Studies, Holistic Health, Job Satisfaction, Military Medicine, Military Personnel, Organizational Innovation, Patient Care Team, Patient-Centered Care, Professional Burnout, Self Care, Surveys and Questionnaires, Workplace

\section{Introduction}

\section{Burnout}

High rates of military and civilian health care professionals suffer from burnout $^{1-5}$ due to both

This article was externally peer reviewed. 2020.

Submitted 30 September 2019; accepted 27 February

From Army Public Health Center, Health Promotion and Wellness Directorate, Public Health Assessment Division, Aberdeen Proving Ground, MD (AMC, JAB); General Dynamics Information Technology, Reston, VA (AMC); Former Oak Ridge Institute for Science and Education participant in support of Army Public Health Center, Health Promotion and Wellness Directorate, Public Health Assessment Division, Belcamp, MD (MMH); Wozniak University, Box Elder, South Dakota $(\mathrm{MMH})$; Madigan Army Medical Center, Joint Base Lewis-McChord, WA (RCO); United States Central Command, Tampa, FL (TSF); Former General Dynamics Information Technology contractor in support of Army Public Health Center, Health personal and environmental factors, including work-life imbalance, having too many competing priorities, administrative demands, inadequate

Promotion and Wellness Directorate, Public Health Assessment Division (LOR).

The authors have no conflicts of interest or financial disclosures to report. The views expressed in this publication are those of the author(s) and do not necessarily reflect the policy of the Department of Defense, the Department of the Army, the Army Medical Department, or the U.S. Government. The work presented within this publication was supported in part by appointments to the Postgraduate Research Participation Program at the Army Public Health Center (APHC), administered by the Oak Ridge Institute for Science and Education through an interagency agreement between the U.S. Department of Energy and APHC.

Corresponding author: Jill A. Brown, 8977 Sibert Rd., Building E-1570, ATTN: MCHB-PH-PHA, Aberdeen Proving Ground, Edgewood Area, MD 21010-5403 (E-mail: usarmy.apg.medcom-phc.mbx.hpw-webcontacts@mail.mil). 
staffing, and lack of professional efficacy. ${ }^{1-4,6-9}$ Burnout is generally defined as the emotional exhaustion and depersonalization that result as an innate stress response to the workplace; some definitions include reduced or perceived lack of personal accomplishment. ${ }^{1-9}$ The literature shows the negative effect burnout has on health care professionals' well-being, quality of patient care, and staff turnover. ${ }^{1-4,7,10}$ Resiliency building training is used to reduce burnout in the workplace; however, recent literature indicates the importance of addressing organizational factors for burnout and implementing organizational changes in combination with resiliency training. ${ }^{1,3,5,8}$

\section{Burnout and the Military Patient-Centered Medical Home (РСMH)}

Military health care professionals experience unique stressors that can exacerbate the risk of burnout, including high demand of services due to ongoing military conflicts and frequent staff turnover due to change in duty station. ${ }^{2}$ Similar to the civilian sector, military primary care has shifted from acute care toward chronic disease management, which led to adoption of the PCMH model in 2009. ${ }^{11}$ The $\mathrm{PCMH}$ model is associated with improved patient satisfaction and decreased burnout in both civilian and military health care team members. ${ }^{12}$ The Army Office of the Surgeon General develops programs to promote holistic health and implemented the Move to Health $(\mathrm{M} 2 \mathrm{H})$ course, which combines self-resiliency training and organizational changes to support military PCMH teams.

In 2013, the Veteran's Health Administration implemented holistic health practices among clinical staff by implementing the "Whole Health: Change the Conversation" course. This course showed improvements from precourse to follow-up in holistic health outcomes, such as intention to engage in holistic health behavior. ${ }^{13}$ In 2015, the Army adapted the course for an Army audience and patient population and focused on addressing burnout. The Army course M2H supports the integration of holistic health behaviors into the Army PCMH. Given that the annual cost associated with burnout related to staff turnover and reduced clinical hours is approximately $\$ 7600$ per employed physician each year, there is economic benefit to reducing burnout. ${ }^{14}$
Figure 1. The elements of self-care.

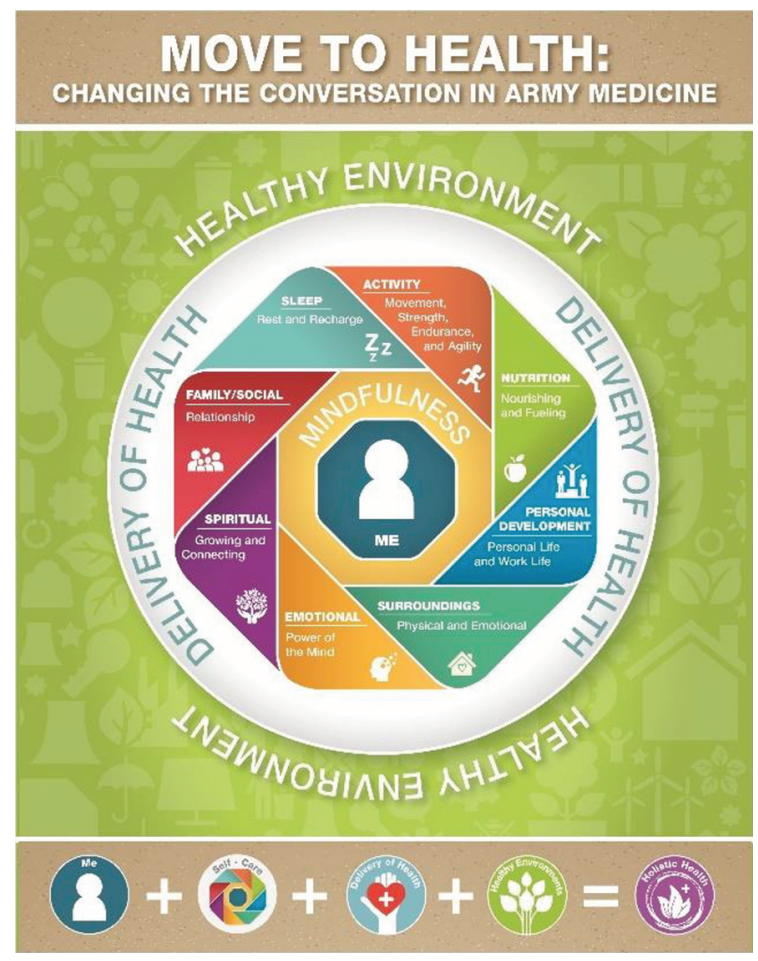

\section{Move to Health}

The $\mathrm{M} 2 \mathrm{H}$ is a 3-day, 20-hour course that focuses on small group work. Day 1 focuses on "experience," which guides health care teams through selfcare elements, such as mindfulness and mindful movements, self-assessment, and communication skills (Figure 1). Day 2 focuses on "practice," where teams learn about the evidence base for holistic approaches to common primary care conditions, such as cardiometabolic disease, gastrointestinal disease, and chronic back pain. Role-play scenarios allow providers to practice motivational interviewing and health coaching skills. Day 3 focuses on "implementation," where teams create short- and long-term action plans to implement $\mathrm{M} 2 \mathrm{H}$ concepts as part of larger organizational change. Thereafter, course facilitators serve as a resource to teams that need additional support to implement the organizational changes outlined in their long-term action plans; there was no predetermined time frame to implement action plans.

The $\mathrm{M} 2 \mathrm{H}$ course goals include improving team members' resiliency and self-efficacy in treating patients holistically, with the ultimate goals of reducing burnout and improving patient care. However, the purpose of this article is to present the evaluation of $\mathrm{M} 2 \mathrm{H}$ and burnout. 


\section{Methods}

\section{Subjects}

The Army Public Health Center's Public Health Review Board approved this evaluation as ethical public health practice. Between May and September 2015, 8 military clinics chose to have the M2H course and 347 team members participated in it (Table 1). All participating clinics intended to make organizational changes to improve the wellbeing of employees. Course facilitators distributed course information to clinic leads for recruitment, asked health care team members to complete article surveys at precourse and postcourse, and emailed invitations to complete the online follow-up survey 2 months later. This article presents results from only those who completed both pre-course and followup surveys ( $\mathrm{n}=186$ ), as outcomes of interest were collected at those time points.

Table 1. Demographic Variables*

\begin{tabular}{lc}
\hline Variable $($ Valid N) & $\begin{array}{c}\mathrm{n}(\%) \text { of Health Care } \\
\text { Team Members }\end{array}$ \\
\hline Sex $(\mathrm{N}=334)$ & \\
Male & $105(31)$ \\
Female & $229(69)$ \\
Age in years $(\mathrm{N}=335)$ & \\
22-34 & $95(28)$ \\
$35-44$ & $109(33)$ \\
$45-54$ & $85(25)$ \\
$>55$ & $43(13)$ \\
Ethnicity $(\mathrm{N}=334)$ & \\
Asian/Pacific Islander & $31(9)$ \\
African American & $37(11)$ \\
Hispanic/Latino & $45(13)$ \\
White (non-Hispanic or Latino) & $200(60)$ \\
Other & $14(4)$ \\
Prefer not to answer & $7(2)$ \\
Years worked in current location $(\mathrm{N}=333)$ & \\
Less than 1 year & $95(29)$ \\
1-3 years & $136(41)$ \\
$4-7$ years & $69(21)$ \\
8-11 years & $19(6)$ \\
Occupation categorized (N = 318) & $14(4)$ \\
Provider & \\
Nurse & $119(37)$ \\
Other occupation & $157(49)$ \\
\hline & $42(13)$ \\
\hline
\end{tabular}

${ }^{*} \mathrm{n}=374$ at pre-course. Some health care team members declined to answer demographic questions; therefore, valid $\mathrm{N}$ varies for each variable.

\section{Design and Measures}

This evaluation used a pre- and postintervention group survey design. Burnout was assessed with single items for emotional exhaustion and depersonalization adapted from the Maslach Burnout Inventory for the military. ${ }^{15,16}$ Indicators of burnout are reported in 2 categories. Individual resiliency was assessed with single items for job satisfaction and satisfaction with PCMH, 5 items for perceived selfefficacy to treat patients holistically, and open-ended questions about how strategies are used in patient care and personal life. Perceived self-efficacy $\left(\alpha_{\text {pre }}=\right.$ $0.86 ; \alpha_{\text {follow-up }}=0.93$ ) was measured as a mean score of 5 items, with possible scores ranging from 0 to 4 and higher scores indicating higher self-efficacy. Implementation was measured with 3 close-ended questions and 2 open-ended questions.

\section{Statistical Analysis}

Quantitative survey data were analyzed with Statistical Package for the Social Sciences (SPSS) version 21 (IBM Corporation, Armonk, New York). Nonparametric testing examined differences in single item outcomes. The paired-sample $t$ test was used to compare differences in self-efficacy scores. Open-ended survey items were analyzed using a priori-directed content analysis in NVivo 10 (QSR International, Melbourne, Australia), and key findings are summarized herein.

\section{Results \\ Burnout}

At precourse, $52 \%$ of the team members $(\mathrm{n}=96)$ enrolled in $\mathrm{M} 2 \mathrm{H}$ reported at least 1 symptom of burnout (emotional exhaustion or depersonalization) compared with $48 \%(n=90)$ of team members at follow-up; however, these percentages did not statistically differ, with McNemar $\chi^{2}(173)=1.11$ and $\mathrm{P}>.05$ (Table 2).

\section{Resiliency}

Job satisfaction at precourse was high, with $47 \%$ $(\mathrm{n}=86)$ of team members indicating they were "usually" satisfied with their job and 15\% (n = 28) indicating they were "always" satisfied with their job (Table 2). Although Wilcoxon matched pairs test found no significant difference in job satisfaction from precourse to follow-up $(Z=-0.6, P>$ $.05)$, satisfaction with the PCMH statistically increased from precourse to follow-up (Wilcoxon 
Table 2. Outcome Changes over Time $(n=186)$

\begin{tabular}{|c|c|c|c|}
\hline Parameter & Pre-Course & Two-Month Follow-up & $P$ value \\
\hline \multicolumn{4}{|l|}{ Burnout } \\
\hline \multicolumn{4}{|l|}{ Emotional exhaustion } \\
\hline n (\% high) & $71(38 \%)$ & $80(43 \%)$ & \\
\hline \multicolumn{4}{|l|}{ Depersonalization } \\
\hline n (\% high) & $57(31 \%)$ & $56(30 \%)$ & \\
\hline At least 1 burnout symptom & $96(52 \%)$ & $90(48 \%)$ & $>0.05$ \\
\hline Job satisfaction & & & $>0.05$ \\
\hline Never & $0(0 \%)$ & $1(1 \%)$ & \\
\hline Rarely & $2(1 \%)$ & $3(2 \%)$ & \\
\hline Occasionally & $5(3 \%)$ & $8(4 \%)$ & \\
\hline Sometimes & $28(15 \%)$ & $25(13 \%)$ & \\
\hline Frequently & $36(19 \%)$ & $37(20 \%)$ & \\
\hline Usually & $86(46 \%)$ & $83(45 \%)$ & \\
\hline Always & $28(15 \%)$ & $27(15 \%)$ & \\
\hline Satisfaction with PCMH & & & $<0.01$ \\
\hline Never & $6(3 \%)$ & $4(2 \%)$ & \\
\hline Rarely & $10(5 \%)$ & $11(6 \%)$ & \\
\hline Occasionally & $11(6 \%)$ & $12(7 \%)$ & \\
\hline Sometimes & $66(36 \%)$ & $38(20 \%)$ & \\
\hline Frequently & $24(13 \%)$ & $32(17 \%)$ & \\
\hline Usually & $43(23 \%)$ & $51(27 \%)$ & \\
\hline Always & $24(13 \%)$ & $37(20 \%)$ & \\
\hline \multicolumn{4}{|l|}{ Self-efficacy } \\
\hline Mean (SD) & $2.8(0.7)$ & $3.2(0.6)$ & $<0.01$ \\
\hline
\end{tabular}

PCMH, patient-centered medical home; SD, standard deviation.

matched pairs, $Z=-3.2, P<.01)$. In addition, selfefficacy scores were statistically higher at the follow-up $(M=3.2, \mathrm{SD}=0.6)$ relative to the precourse $(M=2.8, \mathrm{SD}=0.7)(t(142)=-7.1, P<.01)$.

On the follow-up survey, team members were asked, "Can you describe how you are applying Holistic Health Concepts to your own life since taking the course?" Team members commonly described an "increased focus on stress management, rest, and life balance" (Figure 2). Team members noted using wellness applications presented in the course to help improve sleep, physical activity, and nutrition. Destressors included practicing yoga, mindfulness meditation, and physical activity. One member noted, "I have decided to incorporate yoga for both the mobility and stress relief benefits. I destress at the gym and by running but it is always good to have another tool to use."

\section{Organizational Changes at Follow-up}

Approximately two-thirds of team members reported being in either the beginning implementation ( $1 \%$ to $10 \%$ complete; $\mathrm{n}=65$, $35 \%$ ) or some implementation (11 to $30 \%$ complete; $\mathrm{n}=66,35 \%$ ) stages (Table 3 ). A larger proportion of team members reported they received support from course facilitators $(n=119,64 \%$, $\mathrm{n}=187)$ than from their local facility $(\mathrm{n}=92$, $46 \%, \mathrm{n}=189$ ) (ns vary based on number of team members who volunteered to respond to each question).

At follow-up, team members were asked to describe their $\mathrm{M} 2 \mathrm{H}$ implementation strategies. The 3 most commonly reported strategies were (1) educating other staff members, (2) using M2H skills in patient care, and (3) team focus on self-care. At follow-up, team members commonly described receiving general encouragement to implement $\mathrm{M} 2 \mathrm{H}$, allowing time for staff education, and using $\mathrm{M} 2 \mathrm{H}$ materials in patient care.

Team members were asked at follow-up to select the top 3 barriers to implementing the $\mathrm{M} 2 \mathrm{H}$ action plan in their clinic from a list. The most common barriers selected were resisting change, needing 
Figure 2. Application of holistic health concepts in personal life word cloud.

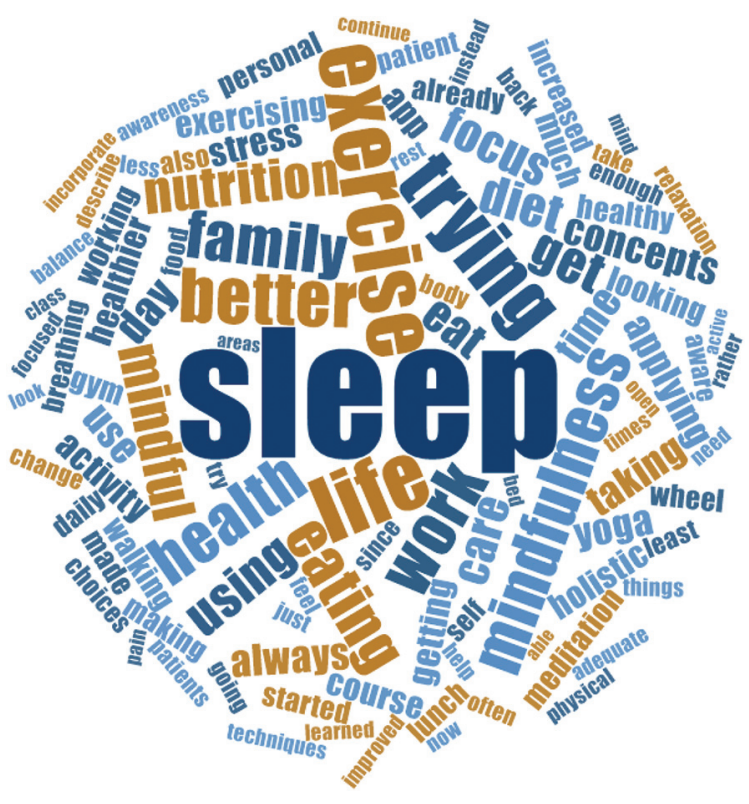

more training for the rest of the health care team, and lacking leadership support.

\section{Discussion}

Although team members began using destressing and resiliency-improving techniques, $\mathrm{M} 2 \mathrm{H}$ was not significantly associated with reduced burnout within a 2-month period following the course. The 2-month time frame may not have been appropriate for measuring changes in perceived burnout-other interventions have measured burnout 1 year after implementation. ${ }^{8}$ Moreover, research indicates resiliency trainings alone are insufficient for reducing burnout. Organizational changes that address causes of burnout, such as lack of fulfillment in the workplace, administrative hassles, and lack of time for patient encounters, are also needed to effectively mitigate burnout. ${ }^{1,2,4,7}$ The clinics reportedly did not fully implement $\mathrm{M} 2 \mathrm{H}$ action plans, which included organizational changes, in the short follow-up period due to resistance to change, need for more training, and lack of leadership support.

The literature suggests that leadership is vital to organizational change to reduce burnout. ${ }^{2,5,6,8,9,17}$ Although clinic leads requested the $\mathrm{M} 2 \mathrm{H}$ course for their health care teams, not all leads attended. In fact, team members commonly suggested leadership attendance could improve the effectiveness of the course. By involving leadership in learning and action planning, the literature suggests teams should receive sufficient leadership support to implement action plans. ${ }^{2,5,6,8,9,17}$ Leadership support and additional staff training could combat the resistance to change.

Limitations of this evaluation include the limitations associated with repeated measures designs, the single item-measurement of some constructs, following up before full action plan implementation, not evaluating the effectiveness of strategies identified in action plans, and survey participant attrition (pre, $n=335$; follow-up, $n=194$ ). Future work may be able to provide a stronger test of burnout mitigation strategies by addressing the limitations noted here.

Table 3. Local Implementation of Move to Health Action Plan*

\begin{tabular}{lcc}
\hline Variable & $\mathrm{n}(\%)$ of Health Care Team Members & Total Valid N \\
\hline Stage of action plan implementation & & 187 \\
$\quad$ Not started (0\% complete) & $16(9 \%)$ \\
Beginning implementation (1\%-10\% complete) & $65(35 \%)$ \\
Some implementation (11\%-30\% complete) & $66(35 \%)$ \\
About half implemented (31\%-50\% complete) & $16(9 \%)$ \\
Mostly implemented (51\%-70\% complete) & $15(8 \%)$ \\
Almost fully implemented (71\%-99\% complete) & $7(4 \%)$ \\
Fully implemented (100\% complete) & $2(1 \%)$ \\
Changed patient interactions, $\mathrm{n}(\%$ yes) & $141(87 \%)$ \\
Received support from: & $92(47 \%)$ \\
The facility & $97(51 \%)$ \\
Course facilitators & 163 \\
\hline
\end{tabular}

${ }^{*} \mathrm{n}=187$ at follow-up. Some health care team members declined to answer questions; therefore, valid $\mathrm{N}$ varies for each variable. 
Although participants in this particular course did not show reductions in burnout, there may be value in similar future efforts. By providing resiliency training in combination with organizational change, organizations can positively impact clinic team members' holistic well-being, turnover potential, and the quality of patient care they provide.

The authors thank Tracy Gaudet, MD, Whole Health team at VHA, Katherine Atwood, SCD, and the Pacific Institute for Research and Evaluation team at Louisville for their support in adapting the course and evaluation tools. The authors recognize the other members of the Move to Health Development Team, from the Army Office of the Surgeon General COL Goodman and LTC Amy King. The authors also thank the System for Health Directors BG Jeffery Johnson and COL Deydre Teyhen for their immense support and guidance throughout the planning, development, and execution of the $\mathrm{M} 2 \mathrm{H}$ pilot. The $\mathrm{M} 2 \mathrm{H}$ continues to spread widely throughout Army Medicine because of the dedication and continued teaching of COL(Ret.) John Edwards, COL(Ret.) Angelene Hemmingway, LTC Arlene Ledoux, Dr. Karen Lesniak, and Ms. LaShonya McNeil. In addition, former APHC program evaluators Mr. Alfonza Brown, MPH, Ms. Chizoba Chukwura, MPH, Ms. Justine Springer, MPH, and Ms. Amy Cowell, MPH, were involved in the early stages of project development and provided project guidance and qualitative coding. The authors would like to thank Ms. Claudia Geary, Dr. Clarice Waters, Dr. Stephanie Gomez, and Ms. Ijeoma Mordi for providing thorough feedback and support. Last, the authors would like to give special thinks to the Health Promotion and Wellness Directorate's Steven Bullock, DPT (retired), Theresa Jackson Santo, PhD, and Ms. Laura Mitvalsky for their thoughtful leadership on and support for this evaluation effort.

To see this article online, please go to: http://jabfm.org/content/ 33/3/440.full.

\section{References}

1. Griner PF. Burnout in health care providers. Integr Med 2013;12:22-4.

2. Sargent P, Millegan J, Delaney E, et al. Health care provider burnout in a United States Military medical center during a period of war. Mil Med 2016; 181:136-42.

3. West CP, Dyrbye LN, Erwin PJ, Shanafelt TD. Interventions to prevent and reduce physician burnout: a systematic review and meta-analysis. Lancet 2016;388:2272-81.

4. Nanda A, Wasan A, Sussman J. Provider health and wellness. J Allergy Clin Immunol Pract 2017;5: $1543-8$.
5. Reith TP. Burnout in United States healthcare professionals: a narrative review. Cureus 2018;10:e3681.

6. Boehm L, Collins R, Duffy MB. How to foster joy, resilience and well-being as an antidote to clinician burnout. On-Line Journal of Nursing Informatics 2017;12. Available at: https://search.proquest.com/ docview/1984790424? accountid=190344.

7. Thimmapuram J, Pargament R, Sibliss K, Grim R, Risques R, Toorens E. Effect of heartfulness meditation on burnout, emotional wellness, and telomere length in health care professionals. J Community Hosp Intern Med Perspect 2017;7:21-7.

8. Gregory ST, Menser T, Gregory BT. An organizational intervention to reduce physician burnout. J Healthc Manag 2018;63:338-52.

9. Stearns S, Shoji K, Benight CC. Burnout among US Military behavioral health providers. J Nerv Ment Dis 2018;206:394-409.

10. Belton S. Caring for the caregivers: making the case for mindfulness-based wellness programming to support nurses and prevent staff turnover. Nurs Econ 2018;36:191-4.

11. Mundell BF, Friedberg MW, Eibner C, Mundell WC. US Military primary care: problems, solutions, and implications for civilian medicine. Health Aff 2013;32:1949-55.

12. Alban J, Anderson K, Beatty K, Grubbs K, Moeller J, Sweeney MK. The RN care manager role within the veterans health administration. American Academy of Ambulatory Care Nursing Viewpoint 2017;39:4-7.

13. Atwood K, Collins D, Scarbrough W, Shamblen S. Whole Health: Change the Conversation Clinical Course: Final Evaluation Report. Pacific Institute for Research and Evaluation: Beltsville, MD; 2014.

14. Han S, Shanafelt TD, Sinsky CA, et al. Estimating the attributable cost of physician burnout in the United States. Ann Intern Med 2019;170:784-90.

15. West CP, Dyrbye LN, Satele DV, Sloan JA, Shanafelt TD. Concurrent validity of single-item measures of emotional exhaustion and depersonalization in burnout assessment. J Gen Intern Med 2012;27:1445-52.

16. West CP, Dyrbye LN, Sloan JA, Shanafelt TD. Single item measures of emotional exhaustion and depersonalization are useful for assessing burnout in medical professionals. J Gen Intern Med 2009;21:1318-21.

17. Laschinger HK, Wong CA, Grau AL. Authentic leadership, empowerment and burnout: a comparison in new graduates and experienced nurses. J Nurs Manag 2013;21:541-52. 